\title{
ПРОГНОСТИЧЕСКАЯ ЗНАЧИМОСТЬ САМООТНОШЕНИЯ В МОДЕЛИРОВАНИИ ИСКУССТВЕННОГО ИНТЕЛЛЕКТА
}

\section{PREDICTIVE SIGNIFICANCE OF SELF-ATTITUDE IN THE MODELING OF ARTIFICIAL INTELLIGENCE}

\section{A. Vislova}

Summary: The article discusses topical issues of the development and implementation of artificial intelligence (AI). The emphasis is on trends in the convergence of science and technology for Al modeling. The problems of psychological analysis of Al and the search for methodological grounds for this are discussed. The influence of self-attitude on intellectual activity and its importance in the development of artificial intelligence systems are analyzed.

Keywords: intellectual activity, artificial intelligence, self-attitude, selfesteem.
Вислова Аминат Даняловна

Д.nсх.н., в.н.с., ФГБНУ «Федеральный научный чентр Кабардино-Балкарского научного чентра Российской академии наук», г. Нальчик avislova@mail.ru

Аннотация: В статье рассматриваются актуальные вопросы разработки и внедрения искусственного интеллекта (ИИ). Делается акцент на тенденции конвергенции наук и технологий в целях моделирования ИИ. Обсуждаются проблемы психологического анализа ИИ и поиск методологических оснований для этого. Анализируется влияние самоотношения на интеллектуальную деятельность и его значение в разработке систем искусственного интеллекта.

Ключевые слова: интеллектуальная деятельность, искусственный интеллект, самоотношение, самооценка.
$\mathrm{H}$ икакие инновации, имевшие место в жизни человека за последние полвека не оказали столь кардинальное воздействие на психику человека, как современные технологии, использующие ИИ. Логично, что решение проблем ИИ потребовало от ученых создать совершенно новую научную культуру, в которой органически слились бы гуманитарные, точные и естественные науки [1]. С учетом интенсивности разработок ИИ, тенденция конвергенции наук и технологий будет только усиливаться.

Однозначного определения понятие «ИИ» ещё не имеет. Однако, существует общее представление об ИИ как системе, обладающей способностью выполнять интеллектуальные функции - обучаться, самообучаться, выполнять анализ, синтез.

Х.Л. Дрейфус формулирует определение, согласно которому ИИ представляет область научных исследований, в которой «цифровые вычислительные машины используются для моделирования разумного поведения...». Автор вносит уточнение: трудности, связанные с разработкой ИИ отражают не столько недостаточное развитие технологии, сколько, указывают на принципиальные границы ее возможностей [2]. Согласно другим ученым, ИИ - «направление науки и техники, ориентированное на создание программно-аппаратных средств решения интеллектуальных задач» [3].

Отечественная психология проявляет довольно робко реагирует на психологический контекст проблемы разработки и внедрения ИИ. Во многом причины этого кроются в том, что психология никак не могла предвидеть столь радикальные изменения, которые происходят в современном технологизированном мире человека. К тому же ИИ зарождался не в недрах психологии и не является предметом психологического изучения [4].

С началом кибернетической эпохи наука о человеческом сознании и психике заговорила языком, ей доселе не свойственным. Она стала членить человеческую психику на блоки, циклы, программы, суб- и метапрограммы. Техноморфизм укоренялся в сознании психологов тем успешнее, чем оптимистичнее были прогнозы исследователей искусственного интеллекта [5].

В своё время, рефлексируя относительно состояния научного знания, автор оригинальной версии системного подхода в психологии Б.Ф. Ломов, отмечал, что «... психологическая наука... вступает в качественно новый этап своего развития... В этих условиях резко возрастает потребность в дальнейшей (и более глубокой) разработке методологических проблем психологической науки» [6]. В настоящее время это утверждение не потеряло своей актуальности и кажется еще более обоснованным. Согласимся, что «любая теория была актуальна в то время, когда она создавалась, давая ответ на вопросы, которые были в то время, но не любая сохранила эту актуальность надолго. Теории, которые относятся к живым, в состоянии дать ответы на сегодняшние вопросы. Поэтому любую теорию важно соотносить с вопросами сегодняшнего дня [7]. А на повестке сегодня остро стоит 
проблема психологического анализа ИИ и поиск методологических оснований для этого.

С целью решения некоторых промежуточных вопросов, связанных с моделированием ИИ, в этом процессе задействованы психологи, философы и др.

По поводу возможности создания ИИ, аналогичного естественному, среди исследователей ведутся серьезные дискуссии. Так, Я.А. Пономарев подчеркивал принципиальное отличие человеческого мышления от «мышления» машинного: «машина способна работать только с системами знаковых моделей и не способна работать с моделями надстроечно-базальными», т.е. субъектными вторичными моделями действительности. Для решения творческих задач, в первую очередь, требуется «способность действовать в уме», отсутствующая у животных, и определяемая высоким уровнем развития внутреннего плана действий. В качестве ментальной единицы творческости мышления Я.А. Пономарев предлагает рассматривать разность уровней, доминирующих при постановке и решении задач [8]. Бесспорно, моделирование ИИ, способного решать творческие задачи - одна из сложнейших проблем.

Сходную точку зрения высказывал А.Г.Спиркин: «Выполнение машиной сложных логических операций не есть ... мышление в строгом смысле ... . Живой мозг решает задачи совсем по-иному. Он работает по направляющему плану, ведущему мысль к определенной, ясно осознаваемой цели. Машина же реализует не свои, а человеческие цели. Решая задачи по определенным формальным правилам, она, конечно, не понимает сути самой задачи и последствий своих действий. Разумеется, человек тоже «программируется» жизнью, обществом. Но он сознательно пользуется этой программой» [9]. Если наличие суммы знаний в программах ИИ вызывает чуть ли не восторг, то отсутствие способности понимать суть выполняемых задач серьезно озадачивает и самих создателей.

С.Ф. Сергеев подчеркивает, что «показатели естественного интеллекта будучи психологическими конструктами, проявляющимися при решении тестовых задач, несмотря на кажущуюся их «объективность», с трудом могут быть применены в технике при оценке систем искусственного интеллекта. Естественный интеллект имеет совсем другую природу, нежели «интеллектуальные возможности», заложенные в сложные технические системы их разработчиками [10]. Однако это не останавливает программистов, которые одержимы идеей воплощения мечты в реальность.

Видный ученый Иванников В.А. обращает внимание на отличительные особенности деятельности психики человека от технологических систем, которые заклю- чаются в том, что «технические устройства (компьютер, телевизор, магнитофон и пр.) только преобразовывают (трансформируют) входящие воздействия и на выходе создают такую их конфигурацию, которая человеком воспринимается и интерпретируется как зрительное изображение или звуковые сигналы. Ни телевизор, ни компьютер сами ничего не видят и не слышат, они трансформируют входящие физические воздействия по правилам, заданным им человеком. Субъект же через психический образ открывает себе поле своей деятельности, но этот процесс открытия совершается за счет собственной активности субъекта и субъективных чувственных переживаний, выполняющих функции строительного материала и языка описания среды, в которой развертывается поведение» [11].

Для того, чтобы называться интеллектуальной, любое техническое устройство должно включать такой компонент как самоотношение. Его игнорирование снимает вопрос о возможности создания автономно функционирующей интеллектуальной системы.

Самоотношение является одним из стержневых конструктов психологических исследований. В отечественной психологии самоотношение рассматривается как составная часть системы отношений человека и психологическая установка (В.Н. Мясищев, Б.Г. Ананьев, С.Л. Рубинштейна, И.И. Чеснокова, Л.И. Божович, И.С. Кон, В.В. Столин, С.Р. Пантелеев и др.).

В теории отношений В.Н.Мясищева самоотношение определяется как единство содержательных и динамических сторон человека, мера осознания и качество эмоционально - ценностного принятия себя как инициативного и ответственного начала социальной активности. В соответствии с данной теорией самоотношение представляет собой установочное образование [12]. Несмотря на важную роль, которую сыграла теория отношений В.Н. Мясищева в отечественной психологии, следует отметить, что в понятиях «отношение» и «самоотношение» прослеживается некоторая расплывчатость и противоречивость взглядов учёного.

Б.Г. Ананьев считал, что самоотношение является наиболее поздним образованием личности, завершающим структуру характера, обеспечивающим его целостность. По его мнению, «отношения к другим превращаются в ... устойчивые образования характера, а затем формируются рефлексивные черты характера из отношений к другим [13]. Он показал наличие определенной последовательности в переходе отношений в свойства характера личности, которая рассматривалась автором как «целая система сознательных отношений к самому себе».

Отношение к себе выполняет функции саморегуляции и самоконтроля, что способствует как образованию, 
так и стабилизации единства личности. По мысли автора, особенности внутренней динамики самосознания, структура и специфика отношения к своему Я регулируют существенные аспекты жизнедеятельности человека; играют определенную роль в развитии межличностных отношений, в процессах мотивации и целеобразовании, а так же в способах формирования и разрешения кризисных ситуаций.

Самоотношение влияет на степень активности человека, ориентированной на самовыражение и самореализацию, тем самым обеспечивая выполнение важной функции самосознания. Вместе с тем самоотношение связано с целями жизни, ценностями и установками. Отмечается, что именно через самоотношение человеку удается раскрыть себя как индивидуальность [14]. Интерпретация самоотношения Б.Г. Ананьевым во многом совпадает с позицией В.Н. Мясищева, хотя есть и свои отличительные особенности. Это вполне логично, учитывая то, что они оба являются соучредителями Ленинградской психологической школы (ещё в советские времена).

По мнению автора понятия «эмоционально-ценностное самоотношение» И.И. Чесноковой, самоотношение - это особый вид эмоционального переживания, связанного с собственным отношением человека к тому, что находит, узнает и понимает относительно себя. При этом эмоциональное переживание характеризуется как внутренняя динамическая и подвижная основа, посредством которой осознается ценностный смысл самоотношения. Эмоциональный параметр составляют чувства и эмоциональные состояния, которые были пережиты в связи с размышлениями о себе и о самопонимании. Присоединяясь к самопознанию, эмоциональный параметр самосознания на некотором зрелом уровне развития делает его по способу осуществления и по своему результату более совершенным; включаясь же в саморегуляцию поведения, способствует ее большей адекватности и дифференцированности [15].

Значительный вклад в изучение проблемы самоотношения внесли В.В. Столин и С.Р. Пантелеев. Основу концепции самосознания В.В. Столина, в рамках которой исследовалось самоотношение, составили идеи А.Н. Леонтьева о деятельности, сознании и личностном смысле как одной из системобразующих элементов самосознания. Самосознание представляет собой процесс, который происходит в условиях переживания конфликтных смыслов, вследствие чего человек начинает осознавать себя и свои качества, а также личностные особенности и ценности, и из этого складывается определенное самоотношение. Согласно В.В. Столину, самоотношение не является следствием знаний о себе или же реакцией на некоторые аспекты своего образа Я. Уточняется, что знание о себе и самоотношение - следствие одних и тех же общих причин, лежащих вне субъекта, в его деятельности, - и только потом, в феноменологически превращенных формах, отдельные самооценки могут восприниматься человеком как способные порождать его подлинное отношение к себе. В.В. Столин отмечал, что самоотношение - это аффективный компонент самосознания. Самоотношение выступает необходимым звеном в самоконтроле поведения и связано с социальным опытом. Опираясь на самопознание самоотношение также создает основные предпосылки для формирования саморегуляции и саморазвития [16].

Научные изыскания В.В. Столина сподвигли С.Р. Пантелеева продолжить исследования проблемы самоотношения. Он подчеркивает, что анализ самоотношения как психической характеристики (эмоциональные состояния, установки и переживания) ограничивает правильное понимание феномена. Самоотношение рассматривается С.Р. Пантелеевым как личностное образование. В самоотношении ученый усматривает динамическую иерархическую систему. Обращается внимание на то, что любая модальность эмоционального отношения может служить ядерной структурой системы и занимать ведущее место в иерархии иных аспектов самоотношения, т.е. фактически определять содержание и выраженность обобщенного устойчивого самоотношения. Раскрыть суть самоотношения человека можно лишь через его составные элементы - деятельность и социальные ситуации развития [17].

В структуре самоотношения С.Р. Пантелеев выделяет оценочную и эмоционально-ценностную подсистемы. Оценочная подсистема обнаруживается в самоуважении, чувстве компетентности и эффективности. Самоуважение включает такие шкалы как саморуководство, самоуверенность, отраженное самоотношение и социальная желательность «Я». Составными элементами эмоционально-ценностной подсистемы являются аутосимпатия, чувство собственного достоинства, самоценность и самопринятие. Допускается также и самоуничижение, которая состоит из внутренней конфликтности и самообвинения. Выделенные подсистемы находятся в постоянном взаимодействии и взаимовлиянии, неодинаково связаны с личностными характеристиками, занимают определенное место в саморегуляции $[18,19]$.

В контексте психологии личности проблема самоотношения отражена в работах Д.А. Леонтьева. В структуре личности он выделяет инстанцию «Я» как форму переживания человеком своей личности, в которой личность открывается сама себе. В инстанции «Я» самоотношение представляет собой одну из граней. В качестве наиболее поверхностного проявления самоотношения рассматривается самооценка, определяемая как общее положительное или же отрицательное отношение к себе. Между тем, лишь одного оценочного знака недо- 
статочно для анализа самоотношения. Делается акцент на различиях между самоуважением и самопринятием. Если самоуважение - это отношение к себе будто бы со стороны, обусловленное некоторыми собственными реальными достоинствами/недостатками, то самопринятие является непосредственным эмоциональным отношение к себе самому, никак не зависящее от наличия каких-то черт, поясняющих это отношение. К существенным характеристикам самоотношения человека относятся также степень его целостности, интегрированности, автономности и независимости от внешних оценок [20]. Можно заметить, что Д.А. Леонтьев выделяет значимые признаки самоотношения человека.

Важно обратить внимание на один момент. Самоотношение, как следует из сказанного, нередко отождествляют с самооценкой, представляющей эмоционально окрашенное отношение к себе в разных ситуациях и в разных видах деятельности. Самооценка - это оценивание собственных личных качеств, достоинств и достижений. С.Л. Рубинштейн указывал на то, что «самооценка человека существенно обусловлена мировоззрением, определяющим нормы оценки» и подчеркивает мысль о том, что «развитие самооценки проходит через ряд ступеней - от наивного неведения в отношении самого себя к все более углубленному самопознанию, соединяющемуся затем со все более определенной и иногда резко колеблющейся самооценкой» [21].

В то время как самооценка характеризуется изменчивостью, самоотношение сохраняет постоянство. Например, сразу же после достигнутого успеха, или же постигшей неудачи самооценка может резко измениться, а самоотношение останется относительно стабильным.

Обобщая вышеизложенное, можно сделать вывод, что самоотношение влияет на характер межличностных отношений и саморегуляцию моделей поведения. Являясь компонентом самосознания, самоотношение оказывает колоссальное влияние на развитие человека и его личностных свойств. Самоотношение участвует во многих когнитивных процессах и влияет на особенности интеллектуальной деятельности, что лишний раз свидетельствует о его значимости в контексте моделирования Ии.

\section{ЛИТЕРАТУРА}

1. Сергеев В. Искусственный интеллект - это еще и экспериментальная философия//Знание-сила, 1989. N 6. С..46-53. http://www.alt-future.narod.ru/Ai/serg. htm. Доступ 17.02.2020.

2. Дрейфус Х.Л. Чего не могут вычислительные машины. Критика искусственного разума. М.: Прогресс, 1978. С. 192.

3. Боровская Е.В., Давыдова Н.А. Основы искусственного интеллекта: учеб. пособ. М.: БИНОМ, Лаборатория знаний, 2017. 127 с.

4. Вислова А.Д. Потенциал психологии интеллекта в контексте моделирования искусственного интеллекта// Известия Кабардино-Балкарского научного центра РАН, 2019. № 6 (92). С.32-48.

5. Ляудис В.Я. Поиски и находки психологии творческой деятельности в области искусственного интеллекта//Вопросы психологии, 1980. http://www. voppsy.ru/issues/1980/804/804171.htm. Доступ: 27.05.2020.

6. Ломов Б.Ф. Методологические и теоретические проблемы психологии. М.: Наука, 1984. С. 4.

7. Леонтьев Д.А. Понятие мотива у А.Н. Леонтьева и проблема качества мотивации//Вестник Московского университета. Серия 14. Психология, 2016. №2. C.4.

8. Пономарёв Я.А. Психология творения. Воронеж, 1999.

9. Спиркин А.Г. Сознание и самосознание. М.: Политиздат, 1972. С.55.

10. Сергеев С.Ф. Искусственный интеллекты в техногенных образовательных средах //0ткрытое образование, 2013. №2. С.52-60.

11. Иванников В.А. 0 природе и происхождении психики//Национальный психологический журнал, 2015. № 3(19). С. 15-23.

12. Мясищев В.Н. Психология отношений: Избранные психологические труды / Под ред. А.А.Бодалева. М.: «Институт практической психологии»; Воронеж: НПО «МОДЭК», 1995. 356 c.

13. Ананьев Б.Г. Избранные психологические труды. Т. 2. М., 1980. С. 45.

14. Ананьев Б.Г. 0 проблемах современного человекознания. Институт психологии. М.: Наука, 1977. 379с.

15. Чеснокова И.И. Проблема самосознания в психологии. М.: Сфера, 2012. 143 с.

16. Столин В.В. Самосознание личности. М.: Просвещение, 2006. 284 с.

17. Пантелеев С.Р. Самоотношение как эмоционально-оценочная система : монография. М.: Издательство Моск. ун-та, 1994. 100 с.

18. Психология. Словарь/ под ред. А.В. Петровского, М.Я. Ярошевского. М.: Просвещение, 2010. 678 с.

19. Пантелеев С.Р. Самоотношение //Психология самосознания: хрестоматия. Самара: БАХРАМ, 2000. С. 208-242.

20. Леонтьев Д.А. Очерк психологии личности: монография. М.: Смысл, 1993. 43 с.

21. Рубинштейн С.Л. Основы общей психологии. СПб., 2002. 720 с. 